\title{
Software Provisioning of the Protech Integrated Engineering Automation System
}

\author{
Rosen Ivanov, Stefan Kartunov \\ Technical university - Gabrovo, department "Mechanical and instrument engineering". \\ Address: Hadji Dimitar 4, Gabrovo 5300,Bulgaria, skartunov@abv.bg, ivanross@abv.bg
}

\begin{abstract}
This is a presentation of the basic principle, operational functions and modules of the software for planning, programming and control of the serial production in the engineering automation system environment. We specified the software provisioning of the particular application and the benefits from its use in the manufacture process. There is a description of the available data bases for the input of the basic technological information about the work-pieces and details and for setting-up of the metal-processing tools. This product traces the technological sequence and the specifics of the production process of machines with computer and numerical control (CNC), the direct connection and dependency of the individual modules within the processing and exchange of the running current information.
\end{abstract}

Keywords: integrated automation system, operational modules, software provisioning

\section{INTRODUCTION}

The reports hitherto presented the main items and positions of this dissertation thesis on automation of engineering design using system for programming, planning and prototyping of the serial machining production. The main functions of these systems are particularly useful in terms of management of the total time and quantity of production; they are based on the material and capacitive economy and perform activities ranging from order processing through accounting control. The system automates the common logistics chain - from distribution and procurement through production and delivery .[3]

Special attention is paid to the present state of the machine-building industry in Bulgaria and the immediate necessity of a system for automation and programming of production, aiming at higher quality of production and shorter periods for order implementation, and a more detailed discussion of the issue is provided in the report "Analysis of the modern machine-building industry in Bulgaria, in terms of utilizing systems for automation and programming in the production"[5]. It contains a detailed analysis of the systems for computer and numerical control (CNC) - Mazak Integrex IV and Siemens - Sinumerik 840D, which will mainly provide support for provisioning of the production cycle, and the topic of the report is "Working with modules for coding programs for control of machines with CNC Mazak Integrex IV and Siemens - Sinumerik 840D in the Protech system environment.[6] A specifically modified technological sequence of work was defined taking into account both systems for $\mathrm{CNC}$ control and programming - part of the topic "Method for technological planning and management of the automated production in the Protech system environment.[7] Defining of the main algorithm of operation for "Protech", and block diagrams for interaction, updating and application of the current information between individual modules of the system in the report "Programming, planning and prototyping of serial production in the Protech integrated engineering automation system environment".[8] The present report continues the direct operation and connection between all of the factors listed hitherto, emphasizing on the software provision of the Protech system.

The main goal of automation of production processes is to reduce the manufacturing periods and to increase the quality of manufactured articles. The mere introduction of machines with computer and numerical control permits quick setup and flexibility. In the same time, extensive work is done concerning the automation of the engineering designers' work, in accordance with the increasing requirements of the market, which cause the necessity of development of more and more complex structures and the corresponding technological processes, within increasingly shorter deadlines. [1]

\section{DESCRIPTION}

The software product is currently in its development process and only part of the hitherto designed software is considered in the present report. These are the modules for provision of the tool equipment, method for input and processing of the parameters of the tools, which will take direct part in the production cycle of the details and work-pieces. The other modules, which are still to be defined, are: module for warehouse management and availability, module for machine provision and the respective equipment, and the module for planning and management of the manufacturing process. The names and definition of the tools are fully compliant with the requirements of the systems for management and programming of CNC machines. When a metal- 
processing tool is added to the program, its operational modes are also to be defined, taking into account the specified and recommended cutting modes, according to the type of the processed material, used by some of the most reputable cutting tools manufacturing companies in the world (Walter, Kennametal, Ceratizit). Within the tool addition process there is an integrated image of the specific tool, so that the programmer setting-up the CNC machine is able to see and evaluate whether the respective tool configuration will be efficient for the particular work process. The software product integrates basic information about machines and systems with CNC control, and this option enables the operator to quickly find more accurate technological decision concerning the sequence and basing of new articles and details in the production process.

The machines with software control are some of the most efficient facilities for automation of the production processes. Their main use is mechanical processing of blanks and details in the conditions of serial, small-number and single item fabrication processes. In its broadest sense, the term software control denotes the expedient definition and the sequential bringing to action of the required operation cycles of the production machine and the simultaneous control of their actual performance and implementation of the processing modes, which provide achieving the quality indicators and productivity designed for the implemented technological operation. [4]

In brief, the goal of the design automation is to increase the quality of the very process, to reduce the cost, to shorten the deadlines for designing and hence, the deadlines for implementation of the article, as a whole. At the present stage, this is implemented by different in complexity, scope and field of application systems for automated design, called generally CAD/CAM systems. [2]

For the development of Protech integrated engineering automation system - automated programming and planning of the production, we used the module for input, operation and analysis of two of the most widely spread systems for control of metalcutting machines with computer and numerical control (CNC) made by the companies Mazak and Siemens Mazatrol - Integrex IV and Sinumerik 840D, respectively. They are extensively applied in the modern machine-building industry and provide a serious pre-requisite for technological development and progress in the sphere of automated design engineering and production. The high technological and technical capacities and the favourable financial factor of these systems for control make them some of the most preferred areas for programming and control in the modern machine-building industry. [6]

When planning and implementing of all main stages of operation with the Protech automation system the input-output data within the system is updated and processed aiming at full efficiency and continuous interdependence between the component modules and the staff operating the system. One of the main advantages of this program is the opportunity to be further developed and upgraded in any software aspect. Each module containing the fundamental data base can be "updated" with new information concerning new articles or details, by adding to them the respective module and data about the necessary new tools and devices, which were not used hitherto in "Protech", or in the machined production. Furthermore, inputting of new technologicalprogramming and structural parameters is also possible using this function. One of the main advantages of this program is the exchange of data between the individual modules of the Protech system, and in this case the accent was put on the sectors for planning, programming and production. The specifics and complexity of articles and details manufactured are evaluated using the data base, which the technologist-programmers operate. The technological sequence of processing is built on basis of this evaluation, designed mainly for machines with a system for control Mazak - Mazatrol or Siemens Sinumerik 840D.[8] Operational programs for the respective systems and machines are compiled, and from an organizational point of view, the necessary appliances, tool equipment and quality control devices must be prepared. The material of the blanks is defined, and in this case there must be a permanent control and information exchange with the warehouse base. The optimum period for implementation of the order is defined upon evaluation of the complexity of the article. During the entire planning, technological and production process of the manufacture, processing and exchange of information between these three sectors is continuous. Detailed block diagram and main operational algorithm for interaction of the above-specified information processes and data transfers can be seen in the article "Programming, planning and prototyping of serial production in the Protech integrated system for automation of engineering design environment" presented at the $9^{\text {th }}$ International conference "Standardization, prototyping and quality: Balkan conference" 5-6 October, 2012, Tirana [8].

\section{OVERVIEW OF THE PROGRAM MENU}

Options of programs menu:

1 - Overview of the main menu;

2 - Description of the tool module;

3 - Management of the tool interchangeability;

4 - Overview of the machine module. 


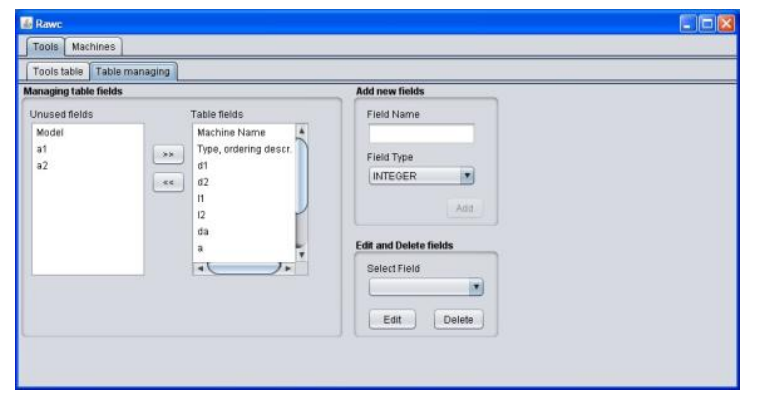

Fig.1 Overview of the main menu of the program

General advantages of the software product: 1 Flexibility of the software product - easy to use, configured and adapted to the specific needs; 2 Planning - allowing planning and optimizing of the processing technology from start to finish; 3 Control and management - better quality and quick production results.

\section{DESCRIPTION OF THE TOOL MODULE}

Management of the main menu of the program. The internal sub-menu Tools managing provides you with the possibility to create a separate sub-window of the Tools managing table. This enables creating new fields, which are suitable for the particular requirements of the user. There are two combined windows of the menu - Unused fields and Table fields. They enable and disable the visibility of the fields in Table fields, by moving within the individual menus using the buttons $<<$ and $>$. The user can add, edit or delete fields with the tool data, depending on the complexity of the tool configuration.

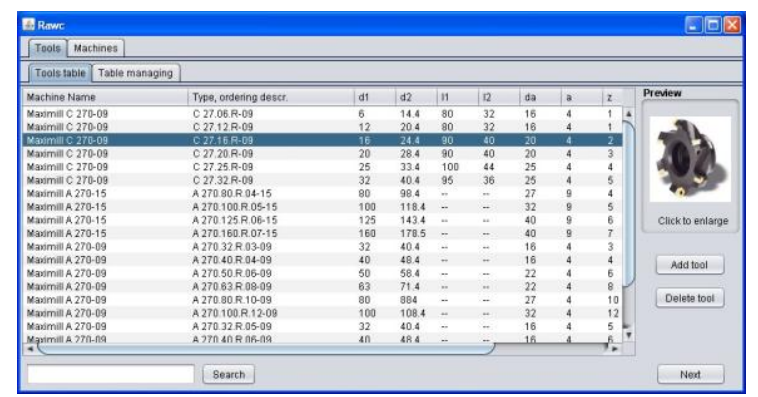

Fig.2 Tools table

When the application is started, it allows you to use the default tool library (Tools table). The table provides detailed information about every tool. From within the preview window, one can see more about the shape of the tool by clicking on the image, obtaining thus full information about the particular metal-processing tool. There is also an option for adding or removing tools from the given menu. This is possible using the buttons Add tool and Delete tool. Even greater convenience is the button Search, through which every match and tool search criteria can be verified.

In the first section of the tool equipment menu are described the types of metal-processing cutters, drills, sink-tools, reamers, and the leftmost column contains the name of the tool, in this case - where the blue marker Maximill C 270-09 is - that is the name (model) of the given tool according to the technical and catalogue documentation of the manufacturing company, and every company has its own name coding. The next column describes in abbreviated manner the geometric parameters of the tool - C 27.16.R-09, in this case the letter "C" means that the cutter is of shank type (the letter "A" denoting shellend cutters), designed for clamping in collet holder or holder of Weldon chuck type (based on autonomous fastening to a specially made site on the oblong part (shank) from the cutter body), the number 27 is the model of the milling tool, the number $\mathrm{d} 1=16 \mathrm{~mm}$ is the diameter of the cutting inserts relative to their frontal direction, $\mathrm{d} 2=24.4 \mathrm{~mm}$ - the diameter of the inserts in radial direction, $11=90 \mathrm{~mm}$ is the length of the entire milling tool including the brazed carbide cutting inserts mounted onto it, $12=40 \mathrm{~mm}$ is the length of the working part of the cutter, $\mathrm{da}=20 \mathrm{~mm}$ diameter of the cutter shank, $a=4 \mathrm{~mm}$ is the height of the bevel of the cutting edge (below 45 grad relative to the front-end and diameter of the cutting edge), $\mathrm{z}=2$ the number of the replaceable carbide cutting inserts fixed onto the cutter. When the application operator selects the desired tool and image of it is shown in the right half of the Tools table window. Upon completion of the development of the tool module, the codes of the tools names will be described in detail according to their manufacturing company, along with all the parameters required for programming and setting-up of machines with CNC control. Using this menu one will also be able to monitor the availability of a given model of tools and when their quantity runs low or is depleted new tools will be ordered.

\section{INPUT OF NEW TOOL}

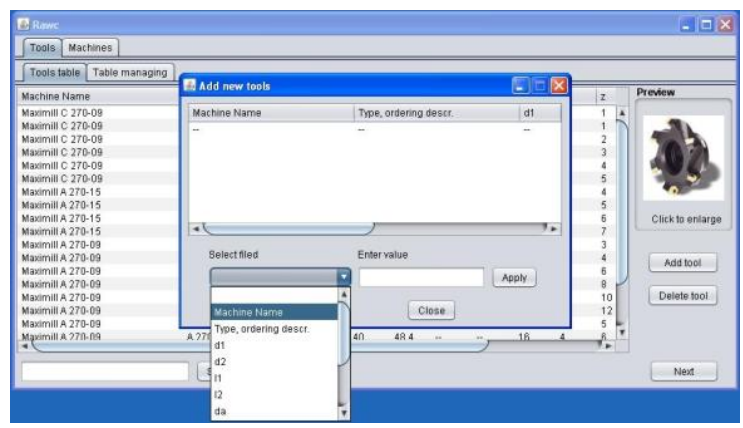

Fig.3 Adding new tool

Fig.3 clarifies the steps for inputting new tool, where by clicking on the menu Add tool a subwindow with the respective name opens, where one can define and store the parameters of the new tool. The operator can first define the name of the metalprocessing tool in the option Machine name, and the next stage is Type ordering descry., which option allows him to select which geometric parameters shall be entered $-\mathrm{d} 1, \mathrm{~d} 2,11,12$ etc. in compliance with the configuration of the tool. Once these positions are 
defined, the operator can click on the button Apply from the program menu so that the data about the new tool will be entered into the data base of the tool module. At the final stage of this manipulation the operator can close the sub-window of the menu using the button Close.

\section{CONCLUSION}

This article reports the beginning of the development of a software product for automation of engineering design in the serial production environment of the machine-building industry. There is a module for inputting of tool equipment, and the steps for setting-up of the necessary information are described in detail. The development of the remaining part of the software product is pending, part of which will be the module for warehouse and availability management, module for machine and the respective equipment provisioning and the module for planning and management of the manufacturing process. The innovations in the software product will be added and described in the presentation attached to the report during the $9^{\text {th }}$ International scientific and practical conference, Rezekne - Latvia 20-22 June.

\section{REFERENCES}

[1] Donkov D., CAD/CAM systems in the machine-building industry - part 1, Gabrovo, Vasil Aprilov University Publishing house, 199

[2] Kartunov S., Rachev P., Automated planning and management of the production. Computer integrated production (CIM), Gabrovo, Printing base of the Technical University - Gabrovo, 1997

[3] Kartunov S., Engineering logistics, Gabrovo, Vasil Aprilov University Publishing house, 2008

[4] Kartunov S., Manual on programming and application of metal-cutting machines with computer and numerical control, Gabrovo, Publishing house of the Technical University Gabrovo, 1996

[5] Ivanov R., Analysis of the modern machine-building industry in Bulgaria, concerning using systems for automation and programming in the manufacture, Scientific session on the occasion of the $50^{\text {th }}$ anniversary from the founding of the Technical University - Varna, 2012

[6] Ivanov R., Kartunov S., Working with modules for programming of control applications for $\mathrm{CNC}$ machines Mazak - Integrex IV and Siemens - Sinumerik 840D in the Protech system environment, XXI international scientifictechnical conference Automation of discrete manufacturing" ADM - 2012" - Sosopol, 2012)

[7] Ivanov R., Rachev P., Method for technological planning and management of the automated production in the Protech system environment, National conference in machinebuilding industry and machine science, International house of scientists „F.J. Curie” Varna-2012)

[8] Ivanov R., Kartunov S., Programming, planning and prototyping of serial production in the Protech integrated system for automation of engineering design environment, 9th International conference "Standardization, prototyping and quality: Balkan conference", Tirana - 2012 